\title{
PRODUKSI KARBON AKTIF DARI BUAH MANGROVE MENGGUNAKAN AKTIVATOR KALIUM HIDROKSIDA
}

\author{
Paryanto", Muhamad Eko Saputro dan Restu Ari Nugroho \\ Program Studi Sarjana Teknik Kimia, Fakultas Teknik, Universitas Sebelas Maret \\ Jl. Ir. Sutami No.36 A, Surakarta \\ *Email: paryanto.uns@gmail.com
}

\begin{abstract}
Abstrak
Konsumsi karbon aktif di Indonesia semakin meningkat seiring dengan meningkatnya penggunaan karbon aktif dalam bidang industri. Mangrove atau yang sering dikenal sebagai pohon bakau di Indonesia merupakan tanaman jenis Rhizopora yang dapat berfungsi sebagai penyaring udara panas dari laut serta penyerap gas karbon di udara. Setiap tahun hutan mangrove dapat menyerap 42 juta ton karbon di udara atau setara dengan emisi gas karbon dari 25 juta mobil. Oleh karena itu, mangrove diproses menjadi karbon aktif agar bisa dimanfaatkan. Bagian dari mangrove yang digunakan untuk pembuatan karbon aktif yaitu buahnya. Pembuatan karbon aktif terdiri dari 2 tahap yaitu proses aktivasi dan proses karbonisasi. Proses aktivasi terbagi menjadi dua, yaitu aktivasi fisika dan kimia. Pada penelitian ini akan dibuat karbon aktif dari buah mangrove menggunakan metode aktivasi kimia, dengan kalium hidroksida $(\mathrm{KOH})$ sebagai aktivatornya. Sedangkan proses karbonisasi menggunakan 2 proses yaitu proses karbonisasi menggunakan furnace. Pada proses karbonisasi menggunakan furnace, bahan baku yang berupa buah mangrove diaktivasi menggunakan aktivator larutan $\mathrm{KOH}$ dengan variasi konsentrasi 0,5 M; $1 \mathrm{M} ; 1,5 \mathrm{M} ; 2 \mathrm{M}$; dan 2,5 M. Proses aktivasi bahan baku ini dilakukan selama 24 jam. Didapatkan luas permukaan karbon aktif optimum diperoleh pada saat konsentrasi $\mathrm{KOH} \mathrm{0,5} \mathrm{M} \mathrm{dengan} \mathrm{luas} \mathrm{permukaan}$ $18,089 \mathrm{~m}^{2} / \mathrm{g}$. Dengan jumlah bahan baku awal sebesar $750 \mathrm{gr}$ didapatkan produk karbon aktif sebesar 273 gr dan yield arang sebesar 36,4\% dengan nilai laju konsumsi bahan bakar adalah 2,326 kg gas LPG/kg karbon aktif.
\end{abstract}

Kata kunci: furnace, karbon aktif, mangrove

\section{PENDAHULUAN}

Karbon aktif merupakan material berkarbon yang dapat diproduksi dengan cara aktivasi fisika dan kimia. Karbon aktif dapat diterapkan di berbagai industri, antara lain untuk pemisahan gas dan pengurangan polusi organik (Nagres, 2009). Karbon aktif dapat dibuat dari limbah pertanian dan kehutanan yang mengandung lignoselulosa karena memiliki kandungan karbon yang tinggi (biasanya lebih dari 45\%) (Ahmedna, dkk., 2000). Limbah pertanian dan kehutanan yang bisa digunakan untuk membuat karbon aktif biasanya berupa cangkang atau kayu, seperti batok kelapa, cangkang kacang kenari, sekam padi, tongkol jagung, dan cangkang coklat.

Mangrove atau yang sering dikenal sebagai pohon bakau di Indonesia merupakan tanaman jenis Rhizopora yang dapat berfungsi sebagai penyaring udara panas dari laut serta penyerap gas karbon di udara. Setiap tahun hutan mangrove dapat menyerap 42 juta ton karbon di udara atau setara dengan emisi gas karbon dari 25 juta mobil (Taufik, 2012). Indonesia memiliki hutan mangrove yang sangat luas sehingga membuka peluang untuk dapat dimanfaatkan sebagai bahan baku pembuatan karbon aktif. Proses pembuatan karbon aktif dari bahan lignoselulosa melibatkan dua prosedur yaitu karbonisasi dan aktivasi (Wang dan Kaskel, 2012). Ada dua metode aktivasi dalam pembuatan karbon aktif yaitu metode aktivasi fisika dan aktivasi kimia (Olivarez, dkk., 2012). Dalam metode aktivasi kimia, bahan baku yang akan digunakan dalam pembuatan karbon aktif direndam dalam aktivator kimia, lalu diikuti dengan karbonisasi (Alslaibi, dkk., 2012). Aktivator yang sering digunakan dalam pembuatan karbon aktif antara lain $\mathrm{H}_{3} \mathrm{PO}_{4}, \mathrm{KOH}, \mathrm{NaOH}, \mathrm{K}_{2} \mathrm{CO}_{3}$, dan $\mathrm{ZnCl}_{2}$. Di antara agen aktivasi kimia yang lain, $\mathrm{KOH}$ biasanya lebih disukai karena lebih ramah lingkungan daripada aktivator lainnya. Keuntungan lain menggunakan $\mathrm{KOH}$ adalah bahwa $\mathrm{K}_{2} \mathrm{CO} 3$ yang terbentuk setelah interaksi antara $\mathrm{KOH}$ dan arang dapat mencegah sampel terbakar yang berlebihan, menghasilkan hasil yang tinggi dan porositas internal yang baik (Abechi, dkk., 2012).

Pada penelitian ini akan dibuat karbon aktif dari buah mangrove menggunakan metode aktivasi kimia, dengan kalium hidroksida 
$(\mathrm{KOH})$ sebagai aktivatornya. Penelitian ini bertujuan untuk mengetahui pengaruh konsentrasi $\mathrm{KOH}$ sebagai aktivator terhadap luas permukaan karbon aktif serta untuk menghitung yield karbon aktif dan laju konsumsi bahan bakar pada saat pembuatan karbon aktif dengan menggunakan furnace.

\section{METODOLOGI}

\section{Bahan}

Bahan yang digunakan dalam penelitian ini adalah batang mangrove, kalium hidroksida $(\mathrm{KOH})$, dan aquadest. Batang mangrove diperoleh dari Cilacap, Jawa Tengah. KOH dan aquadest diperoleh dari toko bahan kimia yang ada di Solo, Jawa Tengah.

\section{Metode \\ Pembuatan karbon aktif dengan furnace}

Batang mangrove dikeringkan di bawah sinar matahari untuk mengurangi kandungan airnya. Setelah kering, bahan baku ditimbang. Kemudian batang mangrove diaktivasi menggunakan aktivator larutan $\mathrm{KOH}$ dengan variasi konsentrasi $0,5 \mathrm{M} ; 1 \mathrm{M} ; 1,5 \mathrm{M} ; 2 \mathrm{M}$; dan 2,5 M. Proses aktivasi bahan baku ini dilakukan selama 24 jam. Selanjutnya batang mangrove yang telah diaktivasi dimasukkan ke alat furnace. Proses ini berlangsung selama 3 jam pada suhu $400^{\circ} \mathrm{C}$ dan dialiri dengan gas $\mathrm{N}_{2}$ dengan laju alir $8 \mathrm{~cm}^{3} /$ detik. Lalu karbon aktif dihaluskan dan dicuci menggunakan aquades hangat.

\section{Pengujian karbon aktif}

Uji BET (Brunauer - Emmett - Teller) pada sampel karbon aktif bertujuan untuk mengetahui luas permukaan tiap sampel karbon aktif. Sampel 10 gram yang sudah sudah menjadi arang ditimbang lalu direndam dalam larutan dengan bahan pengaktif asam fosfat, kmudian dilakukan perendaman perendaman selama 7 jam.

Setelah sampel selesai di rendam kemudian disaring menggunakan kertas whatman dan dikeringkan dalam oven pada suhu $105{ }^{\circ} \mathrm{C}$ sampai berat konstan. Karbon aktif yang telah dihasilkan dicuci menggunakan air panas sampai filtrat mempunyai $\mathrm{pH}$ netral $(\mathrm{pH} 6$ sampai 7) diukur menggunakan kertas $\mathrm{pH}$ universal. Setelah di cuci, karbon aktif tersebut selanjutnya dikeringkan dengan oven pada suhu $110{ }^{\circ} \mathrm{C}$ sampai berat konstan setelah itu karbon siap untuk di ukur luas permukaannya.

\section{HASIL DAN PEMBAHASAN}

\section{Luas permukaan karbon aktif}

Luas permukaan karbon aktif dengan furnace dapat dilihat pada tabel 1 .

Tabel 1. Luas permukaan karbon aktif

\begin{tabular}{ll} 
Konsentrasi & Luas Permukaan BET $\left(\mathrm{m}^{2} / \mathrm{g}\right)$ \\
\hline $0,5 \mathrm{M}$ & 18,089 \\
\hline $1 \mathrm{M}$ & 0,543 \\
\hline $1,5 \mathrm{M}$ & 1,553 \\
\hline $2 \mathrm{M}$ & 15,767 \\
\hline $2,5 \mathrm{M}$ & 0,174 \\
\hline
\end{tabular}

Data di atas menunjukkan bahwa luas permukaan karbon aktif optimum diperoleh pada saat konsentrasi $\mathrm{KOH} 0,5 \mathrm{M}$. Hasil pengujian luas permukaan BET tergolong kecil dikarenakan kurangnya laju alir gas inert pada saat proses karbonisasi menggunakan furnace menyebabkan karbon yang telah terbentuk berubah menjadi abu. Karena pada salah satu percobaan pembuatan karbon aktif laju gas alir $\mathrm{N}_{2}$ sebesar $30 \mathrm{ml} /$ menit (Abechi, dkk., 2013)

\section{Yield karbon aktif dan laju konsumsi bahan bakar spesifik}

Data yang didapatkan adalah sebagai berikut: Besar konsumsi gas: 0,635 kg, Berat batang mangrove: 750 gr, Berat karbon aktif: 273 gr. Dari data di atas didapatkan nilai yield karbon aktif sebesar $36,4 \%$ dan nilai laju konsumsi bahan bakar adalah 2,326 kg gas LPG/kg karbon aktif

\section{KESIMPULAN}

Konsentrasi $\mathrm{KOH}$ optimum dalam pembuatan karbon aktif dari batang mangrove adalah 0,5 $\mathrm{M}$ dengan luas permukaan BET $18,089 \mathrm{~m}^{2} /$ gram. Pada pembuatan karbon aktif batang mangrove didapatkan laju konsumsi bahan bakar spesifik sebesar 2,326 kg gas $/ \mathrm{kg}$ karbon, dan didapatkan nilai yield karbon aktif sebesar $36,4 \%$.

\section{DAFTAR PUSTAKA}

Abechi, dkk., 2013. Preparation and characterization of activated carbon from palm kernel shell by chemical activation [J]. Res J Chem Sci, 3: 54-61.

Ahmedna, dkk., 2000. Production of granular activated carbons from select agricultural 
by-products and evaluation of their physical, chemical and adsorption properties. Bioresour.Technol. 71: 113123.

Aslaibi, dkk., 2012. Comparison of agricultural by-products activated carbon production methods using surface area response Activation processes. Awam International Conference on Civil Engineering (AICCE'12), 528-538.

Diaz, dkk., 2007. Waste materials for activated carbon preparation and its use in aqueous-phase treatment. A review, $J$. Environ. Manage. 85 833-846.

Nagres, B., 2009. Preparation of high surface area activated carbon from corn by chemical activation using potassium hydroxide.University of Calgary.Canada.

Oliveraz, dkk., 2012. Preparation of activated carbon from cherry stones by physical activation in air. Influence of the chemical carbonisation with $\mathrm{H} 2 \mathrm{SO} 4[\mathrm{~J}] . J$ Anal Appl Pyrolysis, , 94: 131-137.

Tufik, Ardiyanto, 2011. Mangrove sebagai penangkap karbon, pendingin udara serta penahan tsunami. www.surveypemetaan.com.

Wang dan Kaskel, 2012. KOH activation of carbon-based materials for energy storage. Journal of Materials Chemistry 22, 23710-23725. 